\title{
Assessment of myofascial stiffness of flexor digitorum superficialis muscles in rock climbers
}

\author{
PIOTR KOCUR ${ }^{1 *}$, IGA PIWIŃSKA², MAGDALENA GOLIWĄS ${ }^{3}$, \\ KATARZYNA ADAMCZEWSKA ${ }^{3}$ \\ ${ }^{1}$ Department of Musculoskeletal Rehabilitation, Poznan University of Physical Education, Poznań, Poland. \\ ${ }^{2}$ Faculty of Physiotherapy, Poznan University of Physical Education, Poznań, Poland. \\ ${ }^{3}$ Department of Musculoskeletal Rehabilitation, Poznan University of Physical Education, Poznań, Poland.
}

\begin{abstract}
Purpose: Myofascial stiffness is the biomechanical property that can be considered as a modifiable risk factor injury of athletes. Moreover, the level of muscle stiffness can be crucial to assessment muscle adaptation to exercise. However, stiffness of flexor muscles in rock climbers has never been investigated. The purpose of this study was to evaluate the myofascial stiffness of the flexor digitorum superficialis (FDS) in the rock climbers. Methods: The group of rock climbers $(n=16)$ has been compared to the non-climbers group $(n=16)$, matched in terms of anthropometric measures and an average level of physical fitness. Moreover, the impact of the one-time rock climbing training on FDS stiffness was assessed in the rock climbers group. The measurement of myotonometric myofascial stiffness of FDS muscles was performed, when the elbow was flexed and fully extended. In both positions, the measurements were taken with the hand open and closed. Results: It has been shown that rock climber's FDS muscle stiffness before training was significantly higher (from 15 to 20\%) compared to non-climbers group. Moreover, after climbing myofascial stiffness of FDS muscles increased significantly from 25 to $40 \%$. Conclusions: Rock climbers have significantly higher stiffness of FDS muscles after rock climbing training. Moreover, the increased stiffness in the FDS differentiates rock climbers from the active and healthy control group. Results may indicate that decrease of muscle stiffness of FDS can be an important factor for the improvement of the climbing effectiveness and prevention of overload in the forearm flexor muscles and their recovery.
\end{abstract}

Key words: stiffness, rock climbing, flexor digitorum superficialis

\section{Introduction}

Rock climbing is a sport increasingly popular worldwide as a recreational activity and a competitive sport. It is also a form of activity that comprehensively involves the entire muscular system. However, the sport of rock climbing has a spectrum of injuries associated with the various risk. Except for the typical direct injury to climbers from falls and rockfalls [1], most of all injuries sustained are associated with overloads in the tendons and muscles. This phenomenon is often connected with insufficient level of physical abilities and with frequently repeated motor activities during rock climbing [21], [25], both among amateurs [46] and professionals [36]. Many injury risk factors were determined. The most important ones seem to be age [42], [44], body mass index (BMI) [39], the rock climbing intensity over a climber's career and more specific as the warm-up quality, middle finger strength or eccentric muscle work used during climbing [2], [46]. Injuries occur the most often $(21-36 \%)$ in the area of muscle-tendon units placed in the hand and fingers [39], [42]. Most of them are located in the tendon and pulley tendon. Less often injuries are associated with a dysfunction of muscles and joints. Closed rupture of the digital flexor tendon pulleys may lead to a significant reduction in sport specific abilities [2], [23], [39], [42].

\footnotetext{
* Corresponding author: Piotr Kocur, Department of Musculoskeletal Rehabilitation, Poznan University of Physical Education, ul. Królowej Jadwigi 27/39, 61-871, Poznań, Poland.

Received: October 27th, 2020

Accepted for publication: March 12th, 2021
} 
High muscle involvement in the forearm area is expressed in changes in the structure of muscle morphology. During climbing, the force level is higher than the theoretical capacities of forearm muscles. Therefore, to produce such high intensities, rock climbers probably have to increase their muscle capacities compared to non-climber populations [8], [48]. The biomechanical studies proved that rock climbing generates large forces on the tendons of flexor digitorum superficialis (FDS) and flexor digitorum profundus (FDP) and the associated interphalangeal joints [41]. Moreover, an electromyographic study indicated FDS highest activity during speed climbing and highlighted the main role of both flexors digitorum during climbing [3], [12].

The importance of cooperation and co-activation of FDS and FDP muscles during the specific grips used in climbing (i.e., "crimp" or "slope") were also emphasized [5], [41], [47]. What is particularly important, climbing can also lead to muscle balance disorders between flexors and extensors of the forearm [48]. Thus, the reports of injuries in rock climbers raise questions regarding the possible prevention of flexor digitorum disorders [5], [23]. The reason is that changes located in these muscles, can result in about $5-20 \%$ of all injuries resulting from overloads in the wrist and forearm region [25], [37]. FDS due to its function and location is one of the most important muscles of which overloads can directly contribute to injury finger tendon or such dysfunctions like carpal tunnel syndrome or golfer's elbow [33].

The studies report that level of muscle stiffness may be associated with worse muscle condition and increased muscle stiffness may be directly associated with exercise-induced muscle damage [15], [22]. It has been proven that, in assessment risk injuries of muscle, tendon and fascia or in improving the performance of athletes, it may be important to make a myotometric examination of muscle stiffness which is relatively easy, determinable and characterized by high repeatability and reliability [18], [24]. However, to best of our knowledge, the assessment of muscle stiffness in rock climbers has not been performed so far.

Nevertheless, studies of other groups of athletes reported that changes in stiffness level can be considered as a modifiable risk factor for injury for track cyclist and netballers [18], [34]. Another study has confirmed that muscle stiffness corresponded well to mediators and markers of the inflammation process in the muscles which appeared after intense exercises [13]. Recent studies have confirmed also, that stiffness measurement can be crucial in determining the recovery and health status of the muscles after running and jumping [20], [40]. Moreover, it was emphasized that the level of muscle stiffness can be crucial to assessment muscle adaptation to exercise [18]. Simultaneously, the optimization of muscle stiffness asymmetry can lead to better sports results in reducing the effect of muscle fatigue in volleyball players [31].

The muscle stiffness research confirms that it could play also a significant role in the muscles and tendon injuries in the upper limb area. For example, the stiffness seems to be an important predictor in the future prevention of overhead-athletes disorders. In the recent study, it has been proven that the stiffness muscle predictor had an impact on the development of tendon injuries in the shoulder area and at the same time it was an important predictive indicator in the prevention of injuries [17].

In accordance with scientific knowledge, rock climbers need significant upper limb capacity in general and forearm flexors in particular [26]. The stiffness of muscles showed good correlations with the variation in grip strength. In their study, Zhou et al. [49] found that grip strength decreases when the stiffness of the forearm muscles increased, which may be crucial for better adaptation for climbing activity. Moreover, it is likely that higher muscle stiffness may limit the static flexibility in the flexor and appropriate function of the forearm extensors [31], [45], [48].

Regular excessive loads of FDS during climbing can lead to severe and most common overload injuries in the forearm and hand area. Intense exertions causes an increase in muscle stiffness which may last from 2 to even 4 days [13], [20]. Therefore, the study of FDS stiffness may be important for the improvement of the climbing effectiveness and prevention of frequent injuries in this form of activity.

The purpose of this pilot study was to evaluate the stiffness of FDS muscle, which is easily accessible and strongly involved during rock climbing. As in other sport disciplines, we had expected that muscle stiffness would be increased, especially in muscle most involved during climbing. It was assumed that FDS stiffness increases significantly after a single workout, irrespective of FDS attachments were close or distance to each other.

Secondly, muscle stiffness has been shown to increase as a result of eccentric or isometric efforts [13], [16] which are typical for climbing activity [8], [10]. Thus, we had anticipated that in various position of FDS at rest, the stiffness may be significantly higher in comparison with the matched control group in terms of anthropometric characteristics. We had proven that even though volunteers from the control group regularly participate in various form of physical activity 
and simultaneously both study groups perform exercises that comprehensively involve the whole muscular system, climbing activities are particularly demanding for the forearm muscles. Therefore, we hypothesized the average values of the stiffness of the FDS muscle at rest could be higher in the group of climbers in comparison to an active control group, even before participation in a typical training for both groups.

\section{Materials and methods}

\section{Participants}

The study included 16 volunteers, regularly practicing climbing (RG - rock climbers group; 11 males and 5 females) The average self-reported climbing ability was 11-12, according to IRCRA Reporting Scale [3]. 16 non-climbers (non-climbers group - NG) were matched in terms of a gender, age, body weight, BMI, the time and frequency of physical activity. Both analyzed groups were limited to the age criteria (higher than 20 and lower than 35 years old), BMI (higher than 18 and lower than 28), the sum of time spent on physical activity $>360$ min (4 training units, per 1.5 hours) and $<720$ min ( 8 training units, per 1.5 hours). The training of the NG-group had consisted of various group activities. The training particularly had focused on aerobic, calisthenic exercises with the functional pattern of the move for muscles of the whole body. The target heart rate zone of this training was, on average, between 60 and $80 \%$ of Heart Rate Reserve. The exclusion criteria was injury and surgery related to forearm and wrist, pain occurrence in the forearm and wrist area within 3 months before the examination. Before data collection, all subjects were asked to read and sign the informed consent. The study was approved by the local ethics committee and conducted in accordance with the Declaration of Helsinki.

\section{Design and procedures}

After collecting anthropometric measures, the measurements of myofascial tissue stiffness of FDS muscles were done using the MyotonPro ${ }^{\circledR}$ device (Myoton AS, Tallinn, Estonia). The tests for both study groups were conducted with a subject being in a sitting position on a chair with adjustable armrests. The subjects were asked to adopt a comfortable sitting position, typical for everyday activities, and relax for a $3 \mathrm{~min}$ utes. The chair height was set towards the entire sole of the foot can rest on the floor and knees and hips was flexed up to 90 degrees. The lumbar and thoracic spine was in neutral and supported on the backrest. The rock climbers were examined at rest before and directly after climbing session, whereas participant form control group were examined once, before their training.

The participants were informed about the details of the procedure, which have proceeded according to the following scheme:

1. The participants were informed that the measurement of myofascial tissue stiffness of FDS muscles would only be taken during static, with fully relaxed muscles, at first while the upper limb was placed on the armrest with the elbow flexed up to 60 degrees, 10 degree of supination (resting position w elbow joint) and 30 degree of the flexion in the shoulder, what was controlled with manual goniometer as in starting position. Individually for every participant, the properly adjusted level of the armrests has been chosen, i.e., the both shoulders were at the same level, in neutral and relaxed position;

2. The second measurement were made, without armrests, with the elbow extended to neutral position, i.e., without any contraction of elbow extensors muscles;

3. In both positions, the measurements were taken with the hand open and closed;

In summary, the measurent of FDS stifness had the followed order:

- Elbow in flexion (Ef) - fingers flexed (Ff),

- Elbow in flexion (Ef) - fingers extended (Fe),

- Elbow in extension (Ee) - fingers flexed(Ff),

- Elbow in extension (Ee) - fingers extended (Fe);

4. The measurements were performed first on the right forearm, and then on the left forearm.

MyotonPro measurement point on the FDS muscles (Fig. 1): in order to obtain the same test standard and procedure, as well as the same point of measure, the FDS muscles were examined in $1 / 3$ distance from the elbow on the line between the medial epicondyle of the humerus and the central point marked by the medical skin marker, on the line connecting the radial and ulnar styloid processes which corresponds to location of trigger point (i.e., hyperirritable spots which are associated with palpable nodules in taut bands of muscle fibers) of FDS muscle. Correct placement of the Myoton in the FDS muscles belly, on every position of the forearm, was checked by instructing the subject to: flex metacarpal joint and the proximal interphalangeal (PIP) joint up to 90 degrees, flex the wrist up to 10 degrees simultaneously keeping the distal interphalangeal joint (DIP) extended, and then 
provide muscle tension with by increased pressure of III and IV finger. When this particular position could not be fixed, the subject had been conducted to attempt movement against the resistance in IV finger. At the same time the rest of fingers should remain extended [24], [31]. Measurements of mechanical muscle parameters were performed once, by the same investigator. The evaluation and measurements took place in the same sport center for both study group, in a separate bright rooms (temp. $18-22{ }^{\circ} \mathrm{C}$ ), at the beginning of the week, before the training in both study group, and after 90 min. climbing training in RG group.

\section{Data analysis}

The measuring process of the FDS stiffness consists of the following parts:

1. Each time, the probe ( $3 \mathrm{~mm}$ diameter) of the device was placed perpendicular to the surface of the skin with constant preload $(0.18 \mathrm{~N})$. Constant prepressure was applied to the skin surface above the FDS muscle belly, thereby slightly compressing the subcutaneous superficial tissues;

2. A light, the quick-released mechanical impulse was exerted by the Myoton at the constant mechanical force on the FDS muscle belly located under the subcutaneous compressed tissues;

3. FDS was responded to the exterior mechanical impulse by a damped natural oscillation. The cooscillation of the FDS, as well as compressed subcutaneous superficial tissues above it and probe, were recorded by an accelerometer in the form of an acceleration graph;

4. Numerical values showing the stiffness of the FDS were then calculated on the basis of the processed oscillation signal.

\section{Dependent variables}

Muscle stiffness $[\mathrm{N} / \mathrm{m}]$, therefore, was expressed as resistance of tissue to an external mechanical impulse. According to recommendation, the myofascial tissue oscillations were evoked with 10 brief $(15 \mathrm{~ms})$ mechanical impulses at a $0.4 \mathrm{~N}$ force and frequency of $1 \mathrm{~Hz}$ [28]. The dynamic myofascial stiffness [N/m] has been calculated according to the following manufacturer's formula [17]:

$$
S=a_{1 \max } \frac{m_{\text {probe }}}{\Delta l},
$$

where: $S$ - the dynamic stiffness; $a_{1 \max }-$ the maximum acceleration where the equilibrium between the impulse force and tissue resistance is achieved (the point in time where the maximum tissue displacement, $m_{\text {probe }}$ - mass of the probe (preload $0.018 \mathrm{~kg}$ ), $\Delta l$ - the maximum tissue displacement amplitude (calculated automatically based on the mathematical algorithms created by the manufacturer of the apparatus) [19], [32].

\section{Statistical analyses}

To assess distribution of the data, the ShapiroWilk test was performed. Values of the analyzed parameters obtained in successive measurements were averaged for each side of the body and then averaged for the both sides. Student's $t$-test for normal data distribution or nonparametric Mann-Whitney $U$-test was used for statistical comparison of the calculated parameters between the groups. Effect size (Cohen's $d$ ) was used to indicate the standardized difference between the means of the compared parameters. Student's $t$-test for normal data distribution or nonparametric Wilcoxon test was used for statistical comparison of the means of two sets of scores between terms. The critical level of significance was set at a $p$-value equal to 0.05 .

\section{Results}

Subjects in both groups did not differ in their basic anthropometric features weekly time spend on physical activity (Table 1).

Table 1. Basic characteristic of studied subjects (Mean \pm SD)

\begin{tabular}{|l|c|c|c|}
\hline \multicolumn{1}{|c|}{ Parameters } & NG $(n=16)$ & RG $(n=16)$ & $p$-value \\
\hline Age [years] & $26.9 \pm 6.1$ & $28.3 \pm 4.6$ & NS \\
\hline Height [cm] & $169.0 \pm 10.5$ & $176.6 \pm 6.8$ & NS \\
\hline Weight $[\mathrm{kg}]$ & $66.7 \pm 13.2$ & $71.3 \pm 11.4$ & NS \\
\hline BMI [kg/m $\left.{ }^{2}\right]$ & $23.6 \pm 3.4$ & $22.8 \pm 2.8$ & NS \\
\hline $\begin{array}{l}\text { Exercise time } \\
\text { per week [hours] }\end{array}$ & $5.6 \pm 2.0$ & $6.1 \pm 1.7$ & NS \\
\hline
\end{tabular}

NG - non rock climbers group, RG - rock climbers group, $\mathrm{BMI}-$ body mass index, NS - not significant for $p<0.05$.

Compared to the CON group, the RG group had a significantly greater stiffness of FDS muscles while the elbow was in extension (Ee), when the fingers were in flexion (Ff) by $20.9 \%$; [325.1 \pm 63.9 in NG and $393.2 \pm 72.8$ in $\mathrm{RG}$; (t) $30=2.1, p<0.05$; Cohen's $d=0.86$ ) and while fingers were extended $(\mathrm{Fe})$ by $15.2 \%$; [328.9 \pm 56.7 in NG and $378.8 \pm 59.5$ in RG; (t) $30=2.2 p<0.05$; Cohen's $d=0.99$ ). There was no significant difference in the stiffness of the 
FDS myofascial tissue while elbow was flexed (Ef) and finger was in flexion (Ff) [314.8 \pm 60.2 in NG and $328.7 \pm 71.4$ in RG; (U) $31=117.5 p=0.76$ (Cohen' $d=0.19)]$ or in extension (Fe) [(323.6 \pm 65.8 in NG and $339.9 \pm 62.8$ in $\mathrm{RG}(\mathrm{U}) 31=108 p=0.47$ (Cohen' $d=0.26$ )] (Fig. 1).

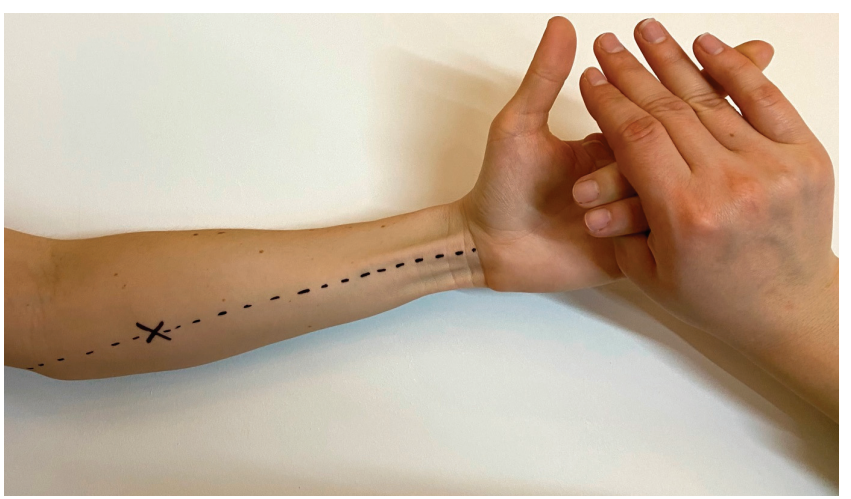

Fig. 1. MyotonPro measurement point on the FDS muscle
It can be observed that there were no significant differences between the study groups while elbow was in flexion and thus the muscle was passively shortened. A phenomenon that differentiated the values of muscle stiffness between the study groups was an increased distance between the muscle attachments, while the elbow was extended.

Irrespectively of position of FDS attachments, after climbing, myofascial stiffness increased significantly when elbow was in flexion (Ef) and finger was in flexion ( $\mathrm{Ff}-$ from $328.7 \pm 71.4$ to $441.1 \pm 110.1$; (W) $31=-3.51 ; p<0.0001 *$ ) or in extension ( $\mathrm{Fe}-$ from $339.9 \pm 62.8$ to $481.2 \pm 163.4$; (W) $31=-3.51 ; p<$ 0.0001). Simultaneously, after climbing, training stiffness in FDS muscle bely increased significantly when elbow was in extension (Ee) and finger was in flexion $(\mathrm{Ff}-$ from $393.2 \pm 72.8$ to $492.7 \pm 72.8$; (t) $31=5.1$; $p<0.0001$ ) and in extension ( $\mathrm{Fe} 378.8 \pm 59.5$ to 502.5 $\pm 131.7,(t) 31=5.3 ; p<0.0001$ ) (Table 2). Similar percentages of changes in muscle stiffness (by $34 \%$

Table 2. Changes in stiffness of FDS after climbing training (Mean $\pm \mathrm{SD}$ )

\begin{tabular}{|l|c|c|c|c|}
\hline \multirow{2}{*}{$\begin{array}{c}\text { Climbing } \\
\text { training }\end{array}$} & \multicolumn{4}{|c|}{ Stiffness FDS [N/m] } \\
\cline { 2 - 5 } & \multicolumn{2}{|c|}{ Elbow flexed (Ef) } & Flbow extended (Ee) \\
\cline { 2 - 5 } & $\mathrm{Ff}$ & $\mathrm{Fe}$ & $393.2 \pm 72.8$ & $\mathrm{Fe}$ \\
\hline Before & $328.7 \pm 71.4$ & $439.9 \pm 62.8$ & $492.7 \pm 72.8^{* *}$ & $502.5 \pm 131.7^{* *}$ \\
\hline After & $441.1 \pm 110.1^{* *}$ & $141.2 \pm 115.1$ & $99.5 \pm 60.4$ & $123.8 \pm 90.4$ \\
\hline Delta & $112.4 \pm 58.8$ & &
\end{tabular}

** - results is significant for $p<0.01 ; \mathrm{Ff}$ - finger flexed, $\mathrm{Fe}$ - finger extended.

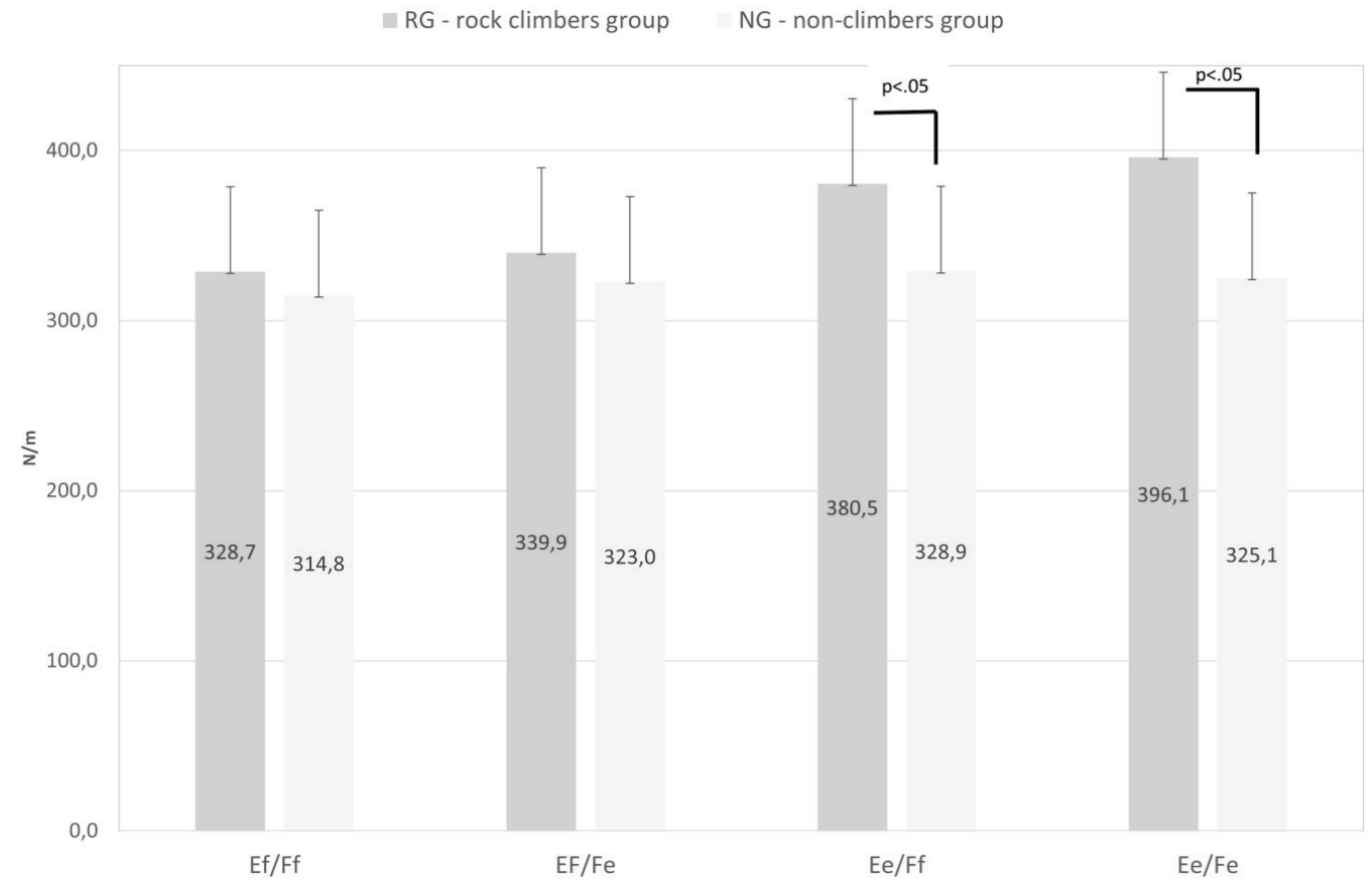

Fig. 2. Comparison of stiffness of FDS muscles between the rock-climbers group and non- climbers group before training; * results is significant for $p<0.05$; abbreviations: $\mathrm{Ff}$ - fingers flexed, $\mathrm{Fe}-$ fingers in extension, Ef - elbow flexed, Ee - elbow extended 
and $41 \%$ ) were observed when the elbow was in flexion when fingers were in flexion (Ef/Ff), and an extension $(\mathrm{Ef} / \mathrm{Fe})$, respectively. When the elbow was in extension, the percentage of changes was $25 \%$ when fingers were in flexion $(\mathrm{Ee} / \mathrm{Ff})$ and $32 \%$ when fingers were in extension $(\mathrm{Ee} / \mathrm{Fe})$. No significant differences in various positions of the elbow and fingers, in the average change of stiffness value before and after training (delta value) were noticed.

\section{Discussion}

The presented cross-sectional pilot study was carried out on a group of rock climbers with a matched control group. The specific group of FDS muscles was analyzed from the point of view of their function during rock climbing and of the injuries possibility due to increased muscle stiffness. The impact of the one-time rock climbing training was presented in this study. The results have shown a significant influence on the muscle stiffness after training, regardless of the muscle position. The analyze has been performed from a position when muscle attachments were significant close to each other (elbow and fingers flexed) to a position where the muscles attachments were maximally distant from each other (without the muscle stretching). At the same time, it has been shown that rock climber's FDS muscle stiffness before training in the position where the muscles attachments were distant from each other is significantly higher compared to subjects who had similar antrhopomotor characteristics and presented a similar level of physical activity. Based on these results, we suppose that higher flexor stiffness may have an impact on the ability to continue climbing, a quickly increased fatigue of the forearm's key muscles, and progressively decreasing in forearm extensor function. Moreover, significantly higher stiffness when attachments FDS are distant from each other in climbers may indicate on reduced flexibility of FDS, and a lower stretch tolerance, what can be connected with a higher risk of a hand injury.

To our knowledge, the relative rock climber's FDS muscle stiffness has not been investigated before this study regarding myotonometry. However, the results of the study are similar to recent reports in which other diagnostic methods have been used or other groups of athletes have been tested. EMG studies indicate the importance of endurance level of flexor digitorum muscles in rock climbers [3], [48]. Vigouroux et al. [48] have investigated relative tendon tensions of FDS and FDP musculotendinous unit during a crimp grip and a slope grip. The authors were focused on particularly high, selective involvement of flexor digitorum muscles which provides flexors and extensors muscle imbalance. Moreover, it has been confirmed that rock climbers had a relatively weaker wrist extensor muscles than the control group. The authors considered that imbalance of muscle tone were one of the risk factors led to a high rate of overuse injuries, with the most common site of injury being in the fingers region. In presented study the stiffness in the extensors have not been assessed but it has been noticed a 15-20 per cent higher stiffness of flexors in rock climbers group, which indicates a permanent changes in the biomechanical properties of the muscles of this origin. As proven in the literature, stiffness reflects the resistance of the tissue to the force that changes its initial shape [9]. A significant disproportion of stiffness between agonists and antagonists was recognized as a risk factor that may affect injuries by reducing joint stability [11]. High muscle stiffness is considered one of the key factors limiting the proper function of agonists and antagonists function. Thus, it may be the biomechanical reason of increasing the muscle imbalance.

Results of this study showed a significant increase from 25 to $41 \%$ (depending on length of the muscle and joint position) of muscle stiffness in the FDS immediately after rock climber's training. Similar results were obtained in previous study showing an increase in Achilles tendon stiffness as an immediate effect after a 16-minute cycle of fights [35]. Also, the maximum effort in the shoulder joint region in various groups of overhead athletes showed a significant increase in stiffness corresponding to changes in muscle structure in ultrasound image [17]. This probably corresponds to a higher risk of impingement syndrome in analyzed area. It was pointed out that in sports characterized by high intensity, a greater component of strength, with appearing of increased muscle stiffness, probably also increases the risk of an overload injury [18]. Therefore, we suppose that significantly increasing of FDS stiffness can be perceived as the risk factor of the overuse forearm injuries in climbers. Moreover, a significant difference in muscle stiffness between RG and CG group was noticed only in the position, when the origin and insertion of the FDS muscle were distant from each other. It may point out to reduction in flexibility of FDS muscles. Studies prove that muscle stiffness and its clinical correlate static flexibility, are the risk factor of more severe muscle damage during and after exercise [29], [43].

Higher forearms muscle stiffness may also be a factor that reduces the effectiveness of climbing. Climb- 
ing is an effort that requires specific muscle strength and endurance, which is based on repetitive movements with isometric tension. The climbing efficiency depends, among others, on the strength and endurance of the muscles of the forearm muscles and fingers [7], [10]. These parts of physical fitness can be strictly connected with muscle stiffness. It was confirmed that with increased muscle stiffness, the muscle strength of forearm muscles was reduced [49]. Thus, earlier reports indicated that aerobic training for forearm muscles may prove a beneficial effect on the efficiency of climbing [7]. Moreover, the ability to climb and its continuation depends on many physiological parameters, such as toleration and removal of lactic acid during climbing and on the oxygenation index of the forearm muscles [10], [26]. Worse microcirculation, which decreases blood flow in stiffer muscles of the forearms, is the performance limiting factor of climbing. It seems that interventions aimed at reducing the stiffness of flexors muscles, both during active breaks during climbing and during recovery, are crucial to increase the efficiency of climbing and reduce muscle fatigue. Although it is impossible to mitonometrically assess the deep-lying belly of FDP. Likely, the observed variations in FDS stiffness will also be noticeable in FDP. The fascicles of fingers dependency and similar function of both muscles mean that they are worked almost simultaneously [5], [14]. Therefore, decreasing muscle stiffness with using, e.g., compression on trigger points or deep massage during rest phases, and stretching of fingers flexors during recovery, can have a noticeable impact on better re-oxygenation of both fingers flexors and simultaneously could be beneficial for better climbing performance.

Regarding the most common flexor tendons injury in rock-climbers, it can be assumed that changes in FDS muscle stiffness probably affect both parts of the muscle, muscle belly and muscle tendons. However, the muscle stiffness probably does not change evenly in the whole muscle region and its tendons. Kawczyński et al. [16] confirmed in their research that the changes in stiffness after exercise were not evenly distributed and the increase of muscle stiffness was probably maintained longer in the tendon than in the muscle belly. Recent reports confirm that muscle stiffness tends to increase significantly as an immediate effect of gastrocnemius loading. These tend were also more noticeable in Achilles tendon than in muscle belly [6] In turn, the results of other studies showed that the effects of increased stiffness in muscle belly can persist after training from 2 to even 4 days [13], [21]. It can be supposed that changes in stiffness appear more quickly in the FDS muscle belly, while in the tendons they are initially less significant, but persist longer, but it required future confirmation.

In summary, many factors may have an influence on the higher FDS muscle stiffness in rock climbers. For example, substantial changes may be observed in ultrasonographic image analysis. A significant change in the thickness of the flexor tendons has been defined in comparison with control group, which indicates the probable specific adaptation of connective tissue in rock climbers [8]. It can be assumed, that probably changes in the structure of the surrounding connective tissue in response to specific repeated motor activity are the cause of increased FDS stiffness as a results of change in structure and morphology of extracellular fascia and collagen cross linking [29], [38]. These changes probably occurred because climbing training requires continuous maneuvering and working with the weight bearing of climber's own body, uses isometric and eccentric muscle work, especially while maintaining own body weight. The high amount of load on the fingers while using the crimp and slope grip is unique in rock climbers and does not occur in any other sport. Therefore, individual grips can lead to increased stiffness in the area of flexors muscles [2], [41]. Nevertheless, according to the current state of knowledge, these hypotheses have not been confirmed, therefore, future research is needed to explain the morphological and structural changes which influenced the higher stiffness of FDS.

\section{Study limitation}

Although presented research might be an important point in the discussion of injury prevention and climbing performance of rock climbers, it should be taken into account that, especially as a pilot study, it had some limitations that should have been considered in the future studies. First, only one of the entire flexor muscle involved during the specific rock climbing has been tested. Despite this fact, FDP were considered as the muscle which is particularly involved to the most popular grip in rock climbing - crimp grip [47]. Dykes et al. [5] in their research confirmed that the FDS and FDP involvement was comparable. Nevertheless, due to the difficult access to small crosssection of FDP tendon the myotonometric testing is not easy to perform. A special method should be developed to perform comprehensive examination of the muscle belly stiffness and muscle tendons stiffness in both flexors and extensors group of muscles in the forearm area for the prevention of injury in climbers. To draw clear conclusions about structural changes in investigated muscle, it would also be necessary to 
combine mytonometric with imaging examination, assessing the structure of muscles and surrounding tissues in the wrist and forearm region of climbers, which was not performed in presented study.

\section{Conclusions}

Rock climbers have significantly higher stiffness of FDS myofascial tissue after rock climbing training. Moreover, the increased stiffness in the FDS muscles differentiates rock climbers from active and healthy control group. Results may indicate muscle stiffness as an important risk factor of overuse injury in the wrist and forearm muscles and tendons in climbers. In addition, a decrease of FDS stiffness can improve the climbing effectiveness and optimize the recovery status of the most involved muscles during climbing. However, to draw clear conclusions future studies should include assessment stiffness of other forearm muscle and its asymmetry.

\section{Acknowledgements}

The study was supported from statutory research funds of the Poznan University of Physical Education (Poland).

\section{References}

[1] Buzzacott P., Schöffl I., ChimiaK J., SchÖFfl V., Rock Climbing Injuries Treated in US Emergency Departments, 2008-2016, Wilderness Environ. Med., 2019, 30 (2), 121-128.

[2] CROWLeY T.P., The flexor tendon pulley system and rock climbing, J. Hand Microsurg., 2012, 4 (1), 25-29.

[3] Deyhle M., Hsu H., Fairfield T., Cadez-Schmidt T., GuRnEY B., MERMIER C., Relative Importance of Four Muscle Groups for Indoor Rock Climbing Performance, J. Strength Cond. Res., 2015, 29 (7), 2006-2014.

[4] Draper N., Giles D., Schöffl V., Fuss F.K., Watts P., Wolf P., Baláš J., Espana-Romero V., Blunt GonZalez G., Fryer S., FAnchini M., Vigouroux L., SeIFert L., Donath L., Spoerri M., Bonetti K., Phillips K., StÖCKer U., Bourassa-Moreau F., GARrido I., DrUM S., BeEKMEYer S., ZiltenER J.-L., TAylor N., Beeretz I., Mally F., AmCa A.M., Linhart C., ABREU E., Comparative grading scales, statistical analyses, climber descriptors and ability grouping: International Rock Climbing Research Association position statement, Sports Technology, 2015, 8, 3-4, 88-94.

[5] DyKes B., Johnson J., SAN JuAn J.G., Effects of finger taping on forearm muscle activation in rock climbers, J. Electromyogr. Kinesiol., 2019, 45, 11-17.

[6] Ericson Morgan G., Martin R., Welch H., Morris K., Quantitative Weight Bearing and non-Weight Bearing Measures of Stiffness in the Achilles Tendon and Gastrocnemius Muscle, MLTJ, 2020, 10 (1), 100-111.
[7] Fryer S., Stone K.J., Sveen J., Dickson T., España-Romero V., Giles D., Baláš J., Stoner L., Draper N., Differences in forearm strength, endurance, and hemodynamic kinetics between male boulderers and lead rock climbers, Eur. J. Sport Sci., 2017, 17 (9), 1177-1183.

[8] Garcia K., JaRAmillo D., RubeSova E., Ultrasound evaluation of stress injuries and physiological adaptations in the fingers of adolescent competitive rock climbers, Pediatr. Radiol., 2018, 48 (3), 366-373.

[9] Gavronski G., Veraksits A., Vasar E., MaAroos J., Evaluation of viscoelastic parameters of the skeletal muscles in junior triathletes, Physiol. Meas., 2007, 28 (6), 625-637.

[10] Giles L.V., Rhodes E.C., Taunton J.E., The Physiology of Rock Climbing, Sports Med., 2006, 36, 529-545.

[11] Granata K., Padua D., Wilson S., Gender differences in active musculoskeletal stiffness. Part II. Quantification of leg stiffness during functional hopping tasks, J. Electromyogr. Kinesiol., 2002, 12 (2), 127-135.

[12] Guo F., Wang Q., Liu Y., Hanson N.J., Changes in blood lactate and muscle activation in elite rock climbers during a 15-m speed climb, Eur. J. Appl. Physiol., 2019, 119 (3), 791-800.

[13] Ho C., Lee M., Chang C., Chen W., Huang W., Beneficial effects of a negative ion patch on eccentric exercise-induced muscle damage, inflammation, and exercise performance in badminton athletes, Chin. J. Physiol., 2020, 63 (1), 35-42.

[14] Hodde F.L., IoAnnou C.I., Altenmüller E., Mapping of finger fascicles within the flexor digitorumsuper ficialis and profundus muscles, Muscle Nerve, 2019, 60, 579-582.

[15] Hug F., Tucker, Kylie Gennisson, Jean-Luc, Tanter M., NORDEZ A., Elastography for Muscle Biomechanics, Exercise and Sport Sciences Reviews, 2015, 43 (3), 125-133.

[16] KawCZyŃSKi A., MroczeK D., ANDERsen R.E., StefaniaK T., ARENDT-Nielsen L., MAdELEINE P., Trapezius viscoelastic properties are heterogeneously affected by eccentric exercise, J. Sci. Med. Sport, 2018, 21 (8), 864-869.

[17] Klich S., Pietraszewski B., Zago M., Galli M., LOVECCHIO N., KAWCZYŃSKI A., Ultrasonographic and Myotonometric Evaluation of the Shoulder Girdle After an Isokinetic Muscle Fatigue Protocol, J. Sport Rehabil., 2019, 7, 1-6.

[18] Klich S., Ficek K., Krymski I., KLimeK A., KawcZyŃski A., Madeleine P., FeRnÁndeZ-DE-LAS-PEÑAS C., Quadriceps and Patellar Tendon Thickness and Stiffness in Elite Track Cyclists: An Ultrasonographic and Myotonometric Evaluation, Front Physiol., 2020, 14, 11, 607208.

[19] Kocur P., TomczaK M., Wiernicka M., Goliwąs M., LEWANDOWSKI J., ŁOCHYŃSKI D., Relationship between age, BMI, head posture and superficial neck muscle stiffness and elasticity in adult women, Sci. Rep., 2019, 11 (1), 8515.

[20] Kong P., Chua Y., Kawabata M., Burns S., Cai C., Effect of Post-Exercise Massage on Passive Muscle Stiffness Measured Using Myotonometry - A Double-Blind Study, J. Sports Sci. Med., 2018, 17 (4), 599-606.

[21] Kozin S., Safronov D., Kozina Z., Kniaz H., Proskurnia O., Prontenko K., Lahno O., Goncharenko V., Kholodniy A., Comparative biomechanical characteristics of one-arm hang in climbing for beginners and qualified athletes, Acta Bioeng. Biomech., 2020, 22 (1), 57-66.

[22] Lacourpaille L., Nordez A., Hug F., Couturier A., Dibie C., Guilhem G., Time-course effect of exerciseinduced muscle damage on localized muscle mechanical properties assessed using elastography, Acta Physiol., 2014, 211 (1), 135-146. 
[23] Lion A., van der Zwaard B.C., Remillieux S., Perrin P.P., Buatois S., Hand injuries in climbing, Scand. J. Med. Sci. Sports, 2016, 26, 739-744.

[24] Liu C.L., Feng Y.N., Zhang H.Q., Li Y.P., Zhu Y., Zhang Z.J., Assessing the viscoelastic properties of upper trapezius muscle: Intra- and inter-tester reliability and the effect of shoulder elevation, J. Electromyogr. Kinesiol., 2018, 43, 226-229.

[25] Logan A.J., Makwana N., Mason G., Dias J., Acute hand and wrist injuries in experienced rock climbers, Br. J. Sports Med., 2004, 38 (5), 545-548.

[26] López Laval I., SitKo S., Performance Factors in Sport Climbing and Bouldering: Systematic Review, J. Sports Training., 2019, 33 (3), 1-10.

[27] LuTSky K.F., Giang E.L., Matzon J.L., Flexor tendon injury, repair and rehabilitation, Orthop. Clin. North Am., 2015, 46 (1), 67-76.

[28] Marusiak J., JaROCKA E., JASKÓLSKA A., JASKÓLSKI A., Influence of number of records on reliability of myotonometric measurements of muscle stiffness at rest and contraction, Acta Bioeng. Biomech., 2018, 20 (4), 123-131.

[29] MaYers T., The Word according the fascia, [in:] Anatomy trains. Myofascial for manual and movement therapist, 2nd Ed., Curchil Livingston, Elsevier, 2009, 9-51.

[30] McHugh M.P., Connolly D.A., Eston R.G., Kremenic I.J., NichOLAS S.J., GLEIM G.W., The role of passive muscle stiffness in symptoms of exercise-induced muscle damage, Am. J. Sports Med., 1999, 27 (5), 594-599.

[31] Mroczek D., Maćkala K., Chmura P., Superlak E., Konefal M., Seweryniak T., Borzucka D., Rektor Z., CHMURA J., Effects of Plyometrics Training on Muscle Stiffness Changes in Male Volleyball Players, J. Strength Cond. Res., 2019, 33 (4), 910-921.

[32] www.Myoton.com/technology, (update on 25th February).

[33] OKAFOR L., VARACALlo M., Anatomy, Shoulder and Upper Limb, Hand Flexor Digitorum Superficialis Muscle.. In: StatPearls (Internet). Treasure Island(FL): StatPearls Publishing; 2020, https://www.ncbi.nlm.nih.gov/books/NBK539723/, (updated Mart 24, 2019).

[34] Pickering Rodriguez E.C., Watsford M.L., Bower R.G., MuRPHY A.J., The relationship between lower body stiffness and injury incidence in female netballers, Sports Biomech., 2017, 16 (3), 361-373.

[35] Pożarowszczyk B., PawlaczyK W., Smoter M., Zarzycki A., MroczeK D., KumoreK M., WitKowsKi K., ADAM K., Effects of Karate Fights on Achilles Tendon Stiffness Measured by Myotonometry, J. Hum. Kinet., 2017, 56, 93-97.
[36] Richter B., Stelzenmueller W., Palpation Techniques: Surface Anatomy for Physical Therapists, Galaktyka, Łódź 2018, 93, 165.

[37] Rohrbough J.T.1, Mudge M.K., Schilling R.C., Overuse injuries in the elite rock climber, Med. Sci. Sports Exerc., 2000, 32 (8), 1369-1372.

[38] Schleip R., Naylor I.L., Ursu D., Melzer W., Zorn A., Wilke H.J., Lehmann-HoRn F., Klingler W., Passive muscle stiffness may be influenced by active contractility of intramuscular connective tissue, Med. Hypotheses, 2006, 66, 66-71.

[39] Schoffl V., POPP D., KuPPER T., SCHOFFl I., Injury trends in rock climbers: evaluation of a case series of 911 injuries between 2009 and 2012, Wilderness Environ. Med., 2015, 26, 62-67.

[40] Schoenrock B., Zander V., Dern S., Limper U., Mulder E., Veraksitš A., VIIR R., Kramer A., StoKes M.J., SAlanOVA M., Peipsi A., BlotTner D., Bed Rest, Exercise Countermeasure and Reconditioning Effects on the Human Resting Muscle Tone System, Front Physiol., 2018, 9, 810.

[41] SCHWEIzER A., Biomechanical properties of the crimp grip position in rock climbers, J. Biomech., 2001, 34 (2), 217-223.

[42] SCHWEIZER A., Sport climbing from a medical point of view, Swiss Med. Wkly, 2012, 11, 142-148.

[43] SCHweIzer A., Lumbrical tears in rock climbers, J. Hand Surg. Br., 2003, 28 (2), 187-189.

[44] WoOllings K., MCKAY C., EMERY C., Risk factors for injury in sport climbing and bouldering: a systematic review of the literature, Br. J. Sports Med., 2015, 49 (17), 1094-1099.

[45] Wilson G.J., Wood G.A., ElliotT B.C., The relationship between stiffness of the musculature and static flexibility: an alternative explanation for the occurrence of muscular injury, Int. J. Sports Med., 199, 12 (4), 403-407.

[46] Van Middelkoop M., Bruens M., Coert J., Selles R., Verhagen E., Bierma-Zeinstra S., Koes B., Incidence and Risk Factors for Upper Extremity Climbing Injuries in Indoor Climbers, Int. J. Sports Med., 2015, 36 (10), 837-842.

[47] Vigouroux L., Quaine F., Labarre-Vila A., Moutet F., Estimation of finger muscletendon tensions and pulley forces during specific sport-climbing grip techniques, J. Biomech., 2006, 14, 2583-2592.

[48] Vigouroux L., Goislard de Monsabert B., Berton E., Estimation of hand and wrist muscle capacities in rock climbers, Eur. J. Appl. Physiol., 2015, 115 (5), 947-995.

[49] Zhou W., Ma X., Pan L., Wang Y., Zhou C., Application of conventional ultrasound coupled with virtual touch tissue imaging and quantification in the assessment of muscle strength, Ann. Palliat. Med., 2020, 9 (5), 3402-3409. 